\title{
EFFECT OF TEMPERATURE CHANGES DURING TRANSPORTATION ON MUESLI QUALITY
}

\author{
Ilva Semicenkova ${ }^{1,2^{*}}$, Sandra Muizniece-Brasava ${ }^{1}$, Asnate Kirse-Ozolina ${ }^{1}$, Martins Sabovics ${ }^{1}$ \\ ${ }^{1}$ Department of Food Technology, Faculty of Food Technology, Latvia University of Life Sciences and Technologies, Rigas iela 22, \\ Jelgava, Latvia,e-mail: ilva.semicenkova@inbox.lv \\ ${ }^{2}$ Felici Ltd, Rigas gatve 8, Adazi, Adazu novads, Latvia
}

\begin{abstract}
Muesli is often packed in pre-made stand-up pouches and flowpacks. There are different storage and packaging solutions based on the composition of the storage atmosphere. Modified atmosphere packaging (MAP) extends shelf-life of product as it affects biochemical, enzymatic and microbiological changes. Nevertheless, during food product transportation around $9 \%$ of complaints are related to wet cargo. It is the second most common problem in freight transportation and causes greatest losses during logistics. A sudden drop in temperature during transportation can cause condensation, increasing moisture migration in the product, reducing its quality and promoting deterioration. The aim of this study was to determine optimal muesli packaging solutions to eliminate the possibility of product quality deterioration due to changes in temperature during muesli transportation. Muesli samples were packed in three different types of packaging - 2-layer (PET/PE) and 3-layer (PAP/AL/PE) stand-up pouches, and biodegradable PLA pouches in air ambience and MAP environment. Samples were stored at ambient temperature $\left(20 \pm 1^{\circ} \mathrm{C}\right)$ for 14 days. After two-week ambient storage, samples were stored at $-5 \pm 1{ }^{\circ} \mathrm{C}, 0 \pm 1{ }^{\circ} \mathrm{C}$ and $30 \pm 1{ }^{\circ} \mathrm{C}$ temperature for 5 days, followed by storage at ambient temperature for 2 days. The results of water activity, moisture content, $\mathrm{pH}$ value, texture and microbiological parameters showed no significant changes in muesli quality.
\end{abstract}

Keywords: muesli, packaging, MAP, temperature changes

\section{Introduction}

Cereals and their products are an important source of energy, carbohydrates, proteins and dietary fibre, which also contain number of micronutrients such as vitamin $\mathrm{E}$, vitamin $\mathrm{B}$, magnesium and zinc, and several bioactive compounds that play an important role in the human diet (McKevith, 2004). Cereals are one of the most important food sources which are used to produce different grain products and animal feed (Wrigley, 2019). Cereal-based food products have been the basis of the human diet since ancient times (Borneo, Leon, 2011). One of the growing grain-based food trends are muesli. Muesli is product made from a mixture of oats and other cereals, dried fruits and nuts and eaten with milk (Complete Oxford Dictionary, 2011).

One of the main factors playing an important role in food quality is packaging. The principal function of packaging is protection and preservation from external contamination. This involves retarding deterioration, extending shelf life and maintaining the quality and safety of packaged food. The package protects food from such environmental influences as heat, light, the presence and absence of moisture, oxygen, pressure, enzymes, undesirable odours, microorganisms etc. (Kour et al., 2013). It is crucial to minimize the rates of biochemical, enzymatic and microbial degradation reactions to extend product shelf life. Commonly it is achieved by using proper sanitation conditions during production. Modified atmosphere packaging (MAP) is defined as the enclosure of packed food with an optimal gas composition that is specially designed to extend its shelf life (Kirtil, Oztop, 2016). Food quality is highly dependent on temperature management. Storage and transportation temperature are the most variable factors influencing product changes which lead to quality deterioration (Rozman et al., 2008).
The aim of this study was to determine optimal muesli packaging solutions to eliminate the possibility of product quality deterioration due to changes in temperature during muesli transportation.

\section{Materials and Methods}

Experiments were carried out at the laboratories of the Faculty of Food Technology, Latvia University of Life Sciences and Technologies.

Raw materials and packaging solutions

All ingredients used for muesli sample preparation were supplied by Felici Ltd. (Table 1).

Table 1

\section{Recipe of muesli used for the research}

\begin{tabular}{lcl}
\hline Ingredients & Amount, \% & $\begin{array}{c}\text { Country of } \\
\text { origin }\end{array}$ \\
\hline Oat wholegrain flakes & 40 & Latvia \\
Toasted triticale & 30 & United \\
wholegrain flakes & & Kingdom \\
Roasted, diced peanuts & 8 & Argentina \\
Whole flaxseeds & 6 & Latvia \\
Chocolate shavings & 6 & Germany \\
Raisins & 6 & Turkey \\
Sunflower seeds & 4 & Bulgaria \\
\hline
\end{tabular}

Muesli samples were packed in three different packaging materials - 3-layer stand-up pouches made from paper, aluminium and polyethylene layers (PAP/AL/PE) (thickness 148 $\pm 2 \mu \mathrm{m}$ ), 2-layer stand-up pouches made from polyethylene terephthalate and polyethylene layers (PET/PE) (thickness 132 $\pm 2 \mu \mathrm{m}$ ) and biodegradable material made from polylactic acid and silicon dioxide layers $\left(\mathrm{PLA} / \mathrm{SiO}_{2}\right)$ (thickness $50 \pm 2 \mu \mathrm{m})$. Two types of packaging environment were used: air ambience and modified air packaging (MAP) $\left(30 \% \quad \mathrm{CO}_{2}, 70 \% \quad \mathrm{NO}_{2}\right)$. The sample weight was 
$250 \pm 1 \mathrm{~g}$. A total of 24 different samples were packed and tested (Table 2).

The prepared samples were stored at ambient temperature $\left(20 \pm 1^{\circ} \mathrm{C}\right)$ for 14 days. After a two-week storage at ambient temperature, samples were moved to different temperature regimes and stored at $-5 \pm 1{ }^{\circ} \mathrm{C}$, $0 \pm 1{ }^{\circ} \mathrm{C}$ and $30 \pm 1{ }^{\circ} \mathrm{C}$ temperature for 5 days, followed by storage at ambient temperature for 2 days before analysis.

Table 2

Sample codes used in the research

\begin{tabular}{|c|c|c|c|}
\hline $\begin{array}{l}\text { Packaging } \\
\text { material }\end{array}$ & $\begin{array}{c}\text { Packaging } \\
\text { environment }\end{array}$ & $\begin{array}{c}\text { Storage } \\
\text { temperature, } \\
{ }^{\circ} \mathbf{C} \\
\end{array}$ & $\begin{array}{l}\text { Sample } \\
\text { codes }\end{array}$ \\
\hline Without any & Air ambience & $20 \pm 1$ & Control* \\
\hline \multirow[t]{8}{*}{ PAP/AL/PE } & Air ambience & $0 \pm 1$ & 1F0 \\
\hline & & $-5 \pm 1$ & 1F5 \\
\hline & & $20 \pm 1$ & $1 \mathrm{~F} 20$ \\
\hline & & $30 \pm 1$ & $1 \mathrm{~F} 30$ \\
\hline & MAP & $0 \pm 1$ & $2 \mathrm{~F} 0$ \\
\hline & & $-5 \pm 1$ & $2 \mathrm{~F} 5$ \\
\hline & & $20 \pm 1$ & $2 \mathrm{~F} 20$ \\
\hline & & $30 \pm 1$ & $2 \mathrm{~F} 30$ \\
\hline \multirow[t]{8}{*}{ PET/PE } & Air ambience & $0 \pm 1$ & $1 \mathrm{P} 0$ \\
\hline & & $-5 \pm 1$ & 1P5 \\
\hline & & $20 \pm 1$ & $1 \mathrm{P} 20$ \\
\hline & & $30 \pm 1$ & $1 \mathrm{P} 30$ \\
\hline & MAP & $0 \pm 1$ & $2 \mathrm{PO}$ \\
\hline & & $-5 \pm 1$ & $2 \mathrm{P} 5$ \\
\hline & & $20 \pm 1$ & $2 \mathrm{P} 20$ \\
\hline & & $30 \pm 1$ & $2 \mathrm{P} 30$ \\
\hline \multirow{8}{*}{$\begin{array}{l}\text { Biodegradable } \\
\mathrm{PLA} / \mathrm{SiO}_{2}\end{array}$} & Air ambience & $0 \pm 1$ & 1B0 \\
\hline & & $-5 \pm 1$ & 1B5 \\
\hline & & $20 \pm 1$ & $1 \mathrm{~B} 20$ \\
\hline & & $30 \pm 1$ & $1 \mathrm{~B} 30$ \\
\hline & MAP & $0 \pm 1$ & $2 \mathrm{~B} 0$ \\
\hline & & $-5 \pm 1$ & 2B5 \\
\hline & & $20 \pm 1$ & $2 \mathrm{~B} 20$ \\
\hline & & $30 \pm 1$ & $2 \mathrm{~B} 30$ \\
\hline
\end{tabular}

* initial sample (before packaging)

\section{Physicochemical quality analysis}

Muesli was grinded in a laboratory mill for moisture, water activity and $\mathrm{pH}$ analysis. Three replicates were tested per analysis for each sample.

Moisture content (\%) was determined by drying at $110 \pm 1{ }^{\circ} \mathrm{C}$ for $2 \mathrm{~h}$ using Memmert drying chamber (GmbH Memmert, Germany).

Water activity $\left(\mathrm{a}_{\mathrm{w}}\right)$ was determined using Novasina LabSwift-aw (Novatron Scientific, UK) equipment.

$\mathrm{pH}$ of muesli was assessed using Jenway $3510 \mathrm{pH}$ meter (Cole-Parmer, UK) after mixing it with distilled water $(10: 1)$.

Hardness (N) was assessed with Texture Analyser TA.HD Plus (Stable Micro Systems, UK) using back extrusion rig with $45 \mathrm{~mm}$ disc. Two types samples were analysed - a dry muesli sample $(20.0 \pm 0.1 \mathrm{~g})$ and a muesli sample $(20.0 \pm 0.1 \mathrm{~g})$ soaked in milk $(50 \pm 1 \mathrm{~mL})$ for 1 minute (Medina et al., 2013). The following parameters were used for the measurements of dry muesli sample: test speed $10 \mathrm{~mm} \mathrm{~s}^{-1}$, distance $10 \mathrm{~mm}$, trigger force $0.049 \mathrm{~N}$. Test speed of $15 \mathrm{~mm} \mathrm{~s}^{-1}$ was used to test muesli sample $(20.0 \pm 0.1 \mathrm{~g})$ soaked in milk.

\section{Microbiological parameters}

Preparation of decimal dilutions for microbiological analysis was carried out according to ISO 6887-4:2017 standard. For yeast and mould determination Malt extract agar medium (Malt extract agar, Ref. 01-111, Scharlau, Spain) was used with incubation at $27 \pm 1{ }^{\circ} \mathrm{C}$ for 48 hours (Kirse et al., 2017). Total microorganism colony count was assessed according to ISO 48331:2013 standard. Colonies of microorganisms were counted using automatic counter (aColyte, Topac Inc., USA). Number of colonies was expressed as colony forming units per gram of product $\left(\mathrm{CFU} \mathrm{g}{ }^{-1}\right)$. Two parallel repetitions per dilution for reliable data were performed.

\section{Data processing}

The obtained data processing was performed using MS Excel 2013 software. ANOVA analysis were performed to determine differences within the samples. Samples were tested in triplicate. Factors were defined as significant if $\mathrm{p}$-value was below 0.05 .

\section{Results and Discussion}

Changes in water activity, moisture content, $p H$ value

Changes in water activity, moisture content and $\mathrm{pH}$ value after storage in different temperatures are shown in Table 3. Water activity influences various biochemical reactions and microbial growth in food products (Syamaladevi et al., 2016). Results show that water activity changes in all samples was insignificant, $\mathrm{a}_{\mathrm{w}}$ ranged between 0.330 to 0.420 . It shows that environment is not beneficial for microbial growth (Madriz-Sanch, 2003). Most noticeable water activity changes were found in sample 2P20 which was packed in 2-layer stand-up pouch (PET/PE).

All muesli ingredients have different moisture content which affects the total moisture level in the mixed muesli. As reported by Kince et al. (2018) toasted grain flakes have up to 4.2 times lower moisture content than rolled grain flakes, therefore suggesting that moisture content of whole muesli should be low. Total moisture content in all samples ranged between 2.95-3.99\%. It was 4 times lower than found in the study by Senhofa et al. (2015), in which the studied muesli did not contain toasted flakes but had a higher proportion of dried fruits. The highest determined moisture content was for 1P30 sample which for dried food products is still low, yet, there were differences of only borderline significance in moisture content among all samples $(p<0.1)$. Temperature changes did not affect moisture of muesli samples, which could be associated with barrier properties of packaging materials moisture migration between environment outside and inside the packaging was not confirmed.

$\mathrm{pH}$ value affects food product quality, mostly colour, sensory parameters and microbial growth (AndresBello et al., 2013). Results showed that $\mathrm{pH}$ value in muesli samples ranged between 5.700 to 6.129 . 
Overall, there were no significant changes in water activity, moisture content and $\mathrm{pH}$ value $(\mathrm{p}>0.05)$ of all tested muesli samples during temperature abuse testing and with regards to the initial muesli sample.

Table 3

Water activity, pH and moisture changes in muesli after storage at different temperatures

\begin{tabular}{lccc}
\hline Samples & $\begin{array}{c}\text { Water activity, } \\
\mathbf{a w}\end{array}$ & $\mathbf{p H}$ & Moisture, \% \\
\hline Control & $0.362 \pm 0.02$ & $5.567 \pm 0.070$ & $3.04 \pm 0.23$ \\
\hline 1F0 & $0.373 \pm 0.02$ & $5.989 \pm 0.098$ & $3.22 \pm 0.10$ \\
1F5 & $0.387 \pm 0.01$ & $5.888 \pm 0.069$ & $3.80 \pm 0.33$ \\
1F20 & $0.378 \pm 0.01$ & $6.129 \pm 0.064$ & $3.85 \pm 0.12$ \\
1F30 & $0.378 \pm 0.01$ & $6.009 \pm 0.115$ & $3.31 \pm 0.16$ \\
2F0 & $0.374 \pm 0.02$ & $5.993 \pm 0.064$ & $3.43 \pm 0.25$ \\
2F5 & $0.380 \pm 0.02$ & $5.973 \pm 0.032$ & $3.99 \pm 0.33$ \\
2F20 & $0.338 \pm 0.01$ & $5.762 \pm 0.132$ & $2.95 \pm 0.27$ \\
2F30 & $0.370 \pm 0.01$ & $5.932 \pm 0.017$ & $3.71 \pm 0.20$ \\
\hline 1P0 & $0.365 \pm 0.01$ & $5.948 \pm 0.031$ & $3.46 \pm 0.10$ \\
1P5 & $0.363 \pm 0.02$ & $5.817 \pm 0.019$ & $3.77 \pm 0.04$ \\
1P20 & $0.346 \pm 0.01$ & $5.734 \pm 0.066$ & $3.37 \pm 0.02$ \\
1P30 & $0.345 \pm 0.01$ & $5.700 \pm 0.033$ & $3.18 \pm 0.24$ \\
2P0 & $0.368 \pm 0.02$ & $6.080 \pm 0.027$ & $3.15 \pm 0.42$ \\
2P5 & $0.364 \pm 0.02$ & $5.925 \pm 0.048$ & $3.18 \pm 0.07$ \\
2P20 & $0.420 \pm 0.01$ & $5.738 \pm 0.074$ & $3.13 \pm 0.25$ \\
2P30 & $0.365 \pm 0.02$ & $5.827 \pm 0.091$ & $3.80 \pm 0.32$ \\
\hline 1B0 & $0.378 \pm 0.02$ & $5.832 \pm 0.107$ & $3.60 \pm 0.41$ \\
1B5 & $0.374 \pm 0.02$ & $5.815 \pm 0.057$ & $3.56 \pm 0.36$ \\
1B20 & $0.389 \pm 0.01$ & $5.991 \pm 0.034$ & $3.97 \pm 0.46$ \\
1B30 & $0.373 \pm 0.01$ & $5.765 \pm 0.046$ & $2.89 \pm 0.04$ \\
2B0 & $0.366 \pm 0.01$ & $5.657 \pm 0.164$ & $3.15 \pm 0.02$ \\
2B5 & $0.369 \pm 0.01$ & $5.962 \pm 0.073$ & $3.56 \pm 0.15$ \\
2B20 & $0.392 \pm 0.01$ & $5.655 \pm 0.048$ & $3.52 \pm 0.30$ \\
2B30 & $0.363 \pm 0.02$ & $5.900 \pm 0.027$ & $3.08 \pm 0.46$ \\
\hline & & &
\end{tabular}

\section{Changes in muesli hardness}

Changes in hardness for dry muesli samples and muesli samples soaked in milk are shown in Figure 1 and Figure 2, respectively. The results indicated that the highest hardness of dry muesli samples was found in sample 2F0, results ranged between 486-1020 N. Whereas, the highest hardness for muesli samples soaked in milk was found in sample 1P30, results ranged between 28-98 N.

One of the main factors affecting the results is the heterogeneous structure of muesli samples (Roos, Drusch, 2016), as the investigated muesli consists of crunchy flakes, seeds, chocolate and soft raisins.

Based on the heterogenous structure, the results both for dry and soaked in milk muesli hardness were inconsistent and scientifically sound conclusions can not be drawn. Therefore, each muesli ingredient should be tested separately. Results show that dry muesli samples were 10 to 17 times harder than muesli samples soaked in milk on average.
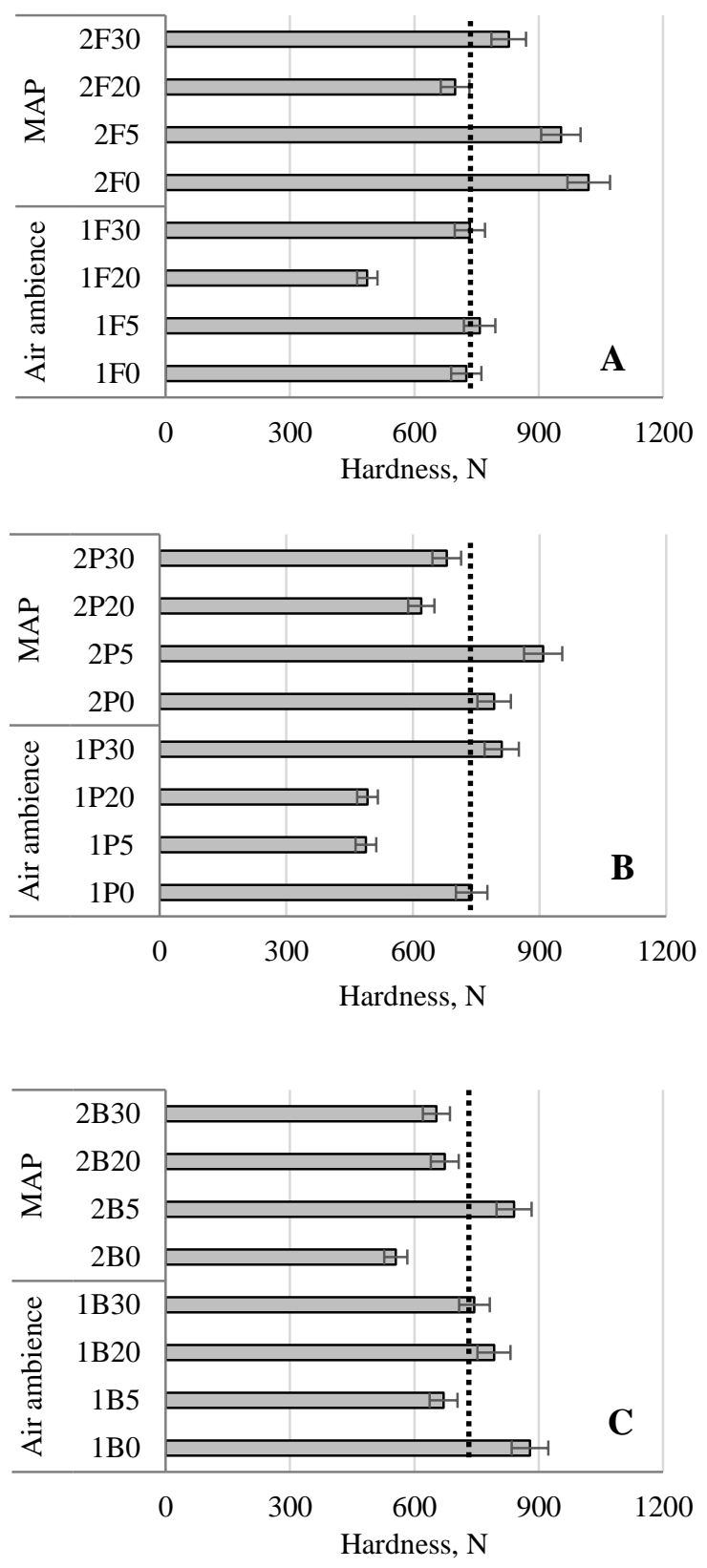

Figure 1. Hardness of dry muesli samples

A - 3-layer stand-up pouches (PAP/AL/PE), B - 2-layer stand-up pouches (PET/PE), C - biodegradable material $\left(\mathrm{PLA} / \mathrm{SiO}_{2}\right)$, ------ initial hardness

\section{Changes in microbiological parameters}

Changes in total microbial count are shown in Table 4. For each package type the lowest amount of mesophilic aerobic and facultative anaerobic microorganisms was detected in samples which were stored at $-5 \pm 1{ }^{\circ} \mathrm{C}$ temperature. For 3-layer stand-up pouches (samples F) and biodegradable material (samples B), the highest total microbial count was determined in samples which were stored at $30 \pm 1{ }^{\circ} \mathrm{C}$ temperature. The results show that in all samples microbial level was low. 

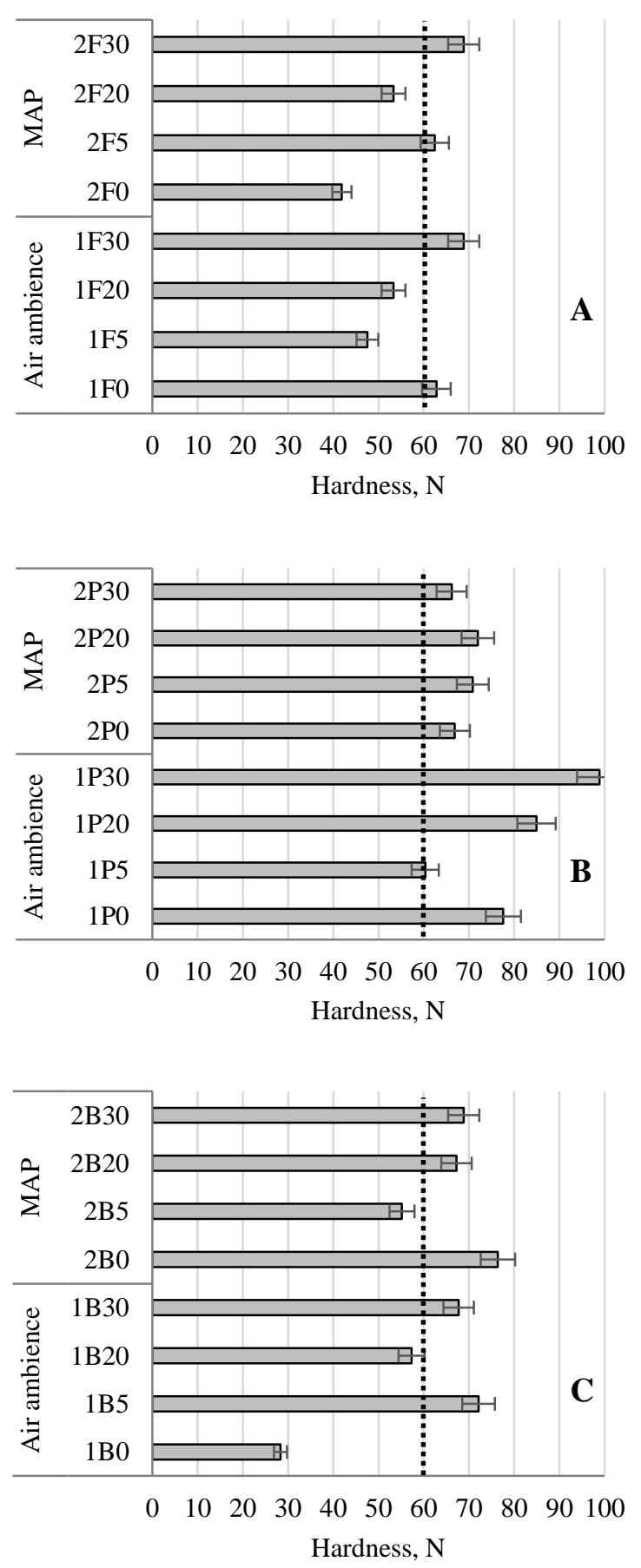

Figure 2. Hardness of muesli samples soaked in milk

A - 3-layer stand-up pouches (PAP/AL/PE), B - 2-layer stand-up pouches (PET/PE), C - biodegradable material $\left(\mathrm{PLA} / \mathrm{SiO}_{2}\right)$, ------ initial hardness

Microorganism growth is affected by moisture content and water activity in food products (Bullerman, Bianchini, 2008) which in all samples was low, thus, we can conclude that packaging environment was not a significant factor for microbial growth in muesli ( $>0.05)$. With regards to admissible level of total plate count, Nerbrink (2007) reported the levels of $10^{4}$ to $10^{5} \mathrm{CFU} \mathrm{g}^{-1}$ as an acceptable limit.
Yeasts were not found in any of the muesli samples. The highest contamination with moulds was detected in samples 2P20 and 1P5, however, there were not significant differences among samples ( $p>0.05)$, and mould count did not exceed $10^{2} \mathrm{CFU} \mathrm{g}^{-1}$. According to ICMFS (2005), the admissible level of yeast and mould count in cereals and similar dry products varies between $10^{2}$ to $10^{4} \mathrm{CFU} \mathrm{g}^{-1}$. There were not significant differences between initial muesli sample and samples after temperature abuse. Senhofa et al. (2015) reported similar results on muesli microbial contamination.

Table 4

Microorganism levels in muesli samples after storage at different temperatures

\begin{tabular}{lcc}
\hline Samples & $\begin{array}{c}\text { Total plate count, } \\
\text { CFU g } \mathbf{g}^{-1}\end{array}$ & $\begin{array}{c}\text { Mould count, } \\
\text { CFU g-1 }\end{array}$ \\
\hline Control & $1.96 \times 10^{1}$ & $2.07 \times 10^{1}$ \\
1F0 & $1.26 \times 10^{2}$ & $3.84 \times 10^{1}$ \\
1F5 & $5.77 \times 10^{1}$ & $4.96 \times 10^{1}$ \\
1F20 & $1.26 \times 10^{2}$ & $2.38 \times 10^{1}$ \\
1F30 & $1.79 \times 10^{2}$ & $5.52 \times 10^{1}$ \\
2F0 & $4.21 \times 10^{1}$ & $6.51 \times 10^{1}$ \\
2F5 & $2.15 \times 10^{1}$ & $3.44 \times 10^{1}$ \\
2F20 & $8.91 \times 10^{1}$ & $3.16 \times 10^{1}$ \\
2F30 & $1.47 \times 10^{2}$ & $2.84 \times 10^{1}$ \\
\hline 1P0 & $1.09 \times 10^{2}$ & $4.21 \times 10^{1}$ \\
1P5 & $5.80 \times 10^{1}$ & $9.61 \times 10^{1}$ \\
1P20 & $8.93 \times 10^{2}$ & $5.58 \times 10^{1}$ \\
1P30 & $1.10 \times 10^{2}$ & $7.05 \times 10^{1}$ \\
2P0 & $2.74 \times 10^{2}$ & $2.78 \times 10^{1}$ \\
2P5 & $4.77 \times 10^{2}$ & $5.64 \times 10^{1}$ \\
2P20 & $1.70 \times 10^{2}$ & $9.63 \times 10^{1}$ \\
2P30 & $1.39 \times 10^{2}$ & $5.79 \times 10^{1}$ \\
\hline 1B0 & $1.26 \times 10^{2}$ & $2.15 \times 10^{1}$ \\
1B5 & $4.21 \times 10^{1}$ & $2.31 \times 10^{1}$ \\
1B20 & $1.05 \times 10^{2}$ & $4.03 \times 10^{1}$ \\
1B30 & $2.02 \times 10^{2}$ & $9.50 \times 10^{1}$ \\
2B0 & $5.25 \times 10^{1}$ & $5.01 \times 10^{1}$ \\
2B5 & $5.80 \times 10^{1}$ & $8.01 \times 10^{1}$ \\
2B20 & $1.42 \times 10^{2}$ & $4.89 \times 10^{1}$ \\
2B30 & $1.63 \times 10^{2}$ & $3.84 \times 10^{1}$ \\
\hline CFU g-1 &
\end{tabular}

$\mathrm{CFU} \mathrm{g}^{-1}-$ colony forming units per gram

It can be concluded that all muesli samples are safe for consumption.

\section{Conclusions}

The results of water activity, moisture content, $\mathrm{pH}$ value, texture and microbiological parameters did not show significant changes for each of the tested parameters. It is suggested to subject muesli samples to additional time-temperature abuse during storage in order to evaluate quality changes throughout extended logistics chain.

\section{Acknowledgment}

This research was supported by Felici Ltd.

\section{References}

1. Andres-Bello A., Barreto-Palacios V., Garcia-Segovia P., Mir-Bel J., Martinez-Monzo J. (2013) Effect of pH on 
color and texture of food products. Food Engineering Reviews, Vol. 5(3), p. 158-170.

2. Borneo R., Leon A. E. (2011) Whole grain cereals: Functional components and health benefits. Food \& Function, Vol. 3(2), p. 110-119.

3. Bullerman L. B., Bianchini A. (2008) Food safety issues and the microbiology of cereals and cereal products. In: Microbiologically safe foods. Chapter - 15. p. 315-335.

4. Complete Oxford Dictionary (2011) Complete Oxford Dictionary 11. Oxford: Bukupedia. p. 3748.

5. ICMFS (International Commission on Microbiological Specifications for Foods) (2005) Cereals and cereal products. Micro-Organisms in foods 6; Microbial ecology of food commodities. New York: Kluwer Academic \& Plenum Publishers, p. 392-439.

6. Kince T., Straumite E., Klava D., Kruma Z., Abelniece K., Balgalve A. (2018) Effects of processing conditions on physical parameters of triticale flakes. Agronomy Research, Vol. 16(2), p. 1417-1424.

7. Kirse A., Skudra L., Karklina D., Galoburda R., Muizniece-Brasava S. (2017) Improvement of microbiological safety and shelf-life of pulse spreads through sous vide and high-pressure processing. Agronomy Research, Vol. 15(2), p. 1304-1315.

8. Kirtil E. Oztop M.H. (2016) Controlled and modified atmosphere packaging. Food Science, Vol. 8(1), p. 1-22.

9. Kour H., Ahmad N., Wani T., Malik A., Kanl R., Chauhan H., Gupta P., Bhat A. (2013) Advances in food packaging - A review. Stewart Postharvest review, Vol. 9(4), p.1-7.
10. Madriz-Sancho M.F. (2003) Encyclopedia of food sciences and nutrition (Second edition). ASV: Academic press, p. 6000.

11. McKevith B. (2004) Nutritional aspects of cereals. Nutrition Bulletin, Vol. 29, p. 11-142.

12. Medina T. W., Quevedo R. A., Aguilera J. M. (2013) Changes on image texture features of breakfast flakes cereals during water absorption. Food Science and Technology International, Vol. 19(1), p. 45-57.

13. Nerbrink E. (2007) Guidelines for product safety; Analyzes and maximum levels. Version 6

14. Roos Y.H., Drusch S. (2016) Phase Transitions in foods. New York: Academic Press. 380 p.

15. Rozman V., Liška A., Volenik M., Kalinovič I., Šmič B. (2008) Influence of relative humidity and temperature to the changes in grain temperature in stored wheat and maize. Agriculture Conspectus Scientificus, Vol. 72(3), p. 215-219.

16. Senhofa S., Straumite E., Sabovics M., Klava D., Galoburda R., Rakcejeva T. (2015) The effect of packaging type on quality of cereal muesli during storage. Agronomy Research, Vol. 13(4), p. 1064-1073.

17. Syamaladevi R. M., Tang J., Villa-Rojas R., Sablani S., Carter B., Campbell G. (2016) Influence of water activity on thermal resistance of microorganisms of low-moisture foods: a review. Comprehensive Reviews in Food Science and Food Safety. Vol. 15(1), p. 353-370.

18. Wrigley C. W. (2019) Swaison's handbook of technical and quality management for the food manufacturing sector. 18 -Cereals. USA: Woodhead publishing. p. 582. 